\title{
Basal-cell Carcinoma of Large Dimension
}

\begin{tabular}{|l|l|l|}
\hline G.F. & Klostermann \\
\hline
\end{tabular}

Göttingen

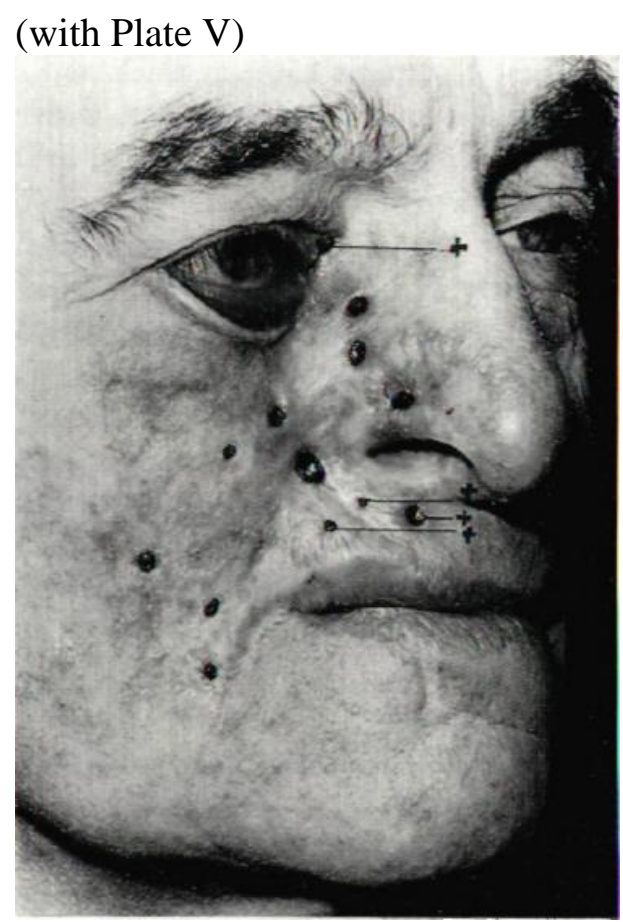

Remark on the Discussion

As to the question of basal-cell carcinoma of large dimension and the effectiveness of external medication with 5-FU, I only want to stress my opinion, that it is the depth and not the flat extent of the tumor's growth, which is the essential factor. And I want to show you an example. In this case of a flat, but large basal-cell epitheli-oma of the face, it has been tried by treatment with 5FU ointment to restrict a very extensive operation or radiation therapy, which would otherwise have been necessary and which, in both cases, would as a consequence have led to severe deformations (fig. 1-4).

Fig. 4 